\title{
Разработка сайта ООО ПКФ «ВИСТ»
}

\author{
Идаятов Т.А., студент, \\ Технический институт (филиал) \\ Северо-Восточного федерального университета, \\ 2. Нерюнгри \\ E-mail: rom_ykt@mail.ru
}

\section{Научный руководитель: к.г.-м.н., доцент Мололкина О.Л.}

На сегодняшний день, интернет магазины имеет большую популярность из-за своих неоспоримых плюсов: Экономия времени, полноценные характеристики товаров, удобная навигация по магазину, возможная доставка до клиента.

CMS (Content Management System) - это система управления содержимым сайта. Различные CMS были созданы для упрощения процесса управления контентом на webплощадке. CMS популярны, а это значит, что если у вас возникнут трудности, то вы всегда сможете найти людей, которые также используют вашу CMS, и которые уже сталкивались с такой проблемой. Как правило таких людей очень много, и решения могут быть универсальными для всех.

Для разработки сайта выбрана бесплатная платформа CMS WordPress из-за еe простоты и удобства, а также, как я упомянул выше, из-за ее цены. Также существуют такие преимущества у Worpress:

- Выбор шаблонов Вордпресс достаточно большой;

- Быстрая установка;

- Понятная и простая панель управления (админка);

- Большой выбор доступных дополнений и расширений (плагины);

- Возможность вносить изменения в код шаблона.

- Движок и шаблоны к нему можно скачать бесплатно;

Добавлять контент на сайт можно с помощью визуального редактора, который достаточно прост в использовании. Админ-панель интуитивно понятна всем и каждому, освоить ее можно в короткие сроки. Чтобы расширить функциональные возможности сайта, достаточно установить необходимые плагины. Основные плагины в свободном доступе. При желании изменить отображение, стиль или структуру сайта, надо корректировать код в файлах темы. Структура шаблона Вордпресс, иерархия его файлов также относительно проста, в сравнении с CMS Joomla.

Сайты, разработанные на WordPress защищены от заражений вирусами, а также от взломов. У CMS WordPress не требовательна к ресурсам сервера, на котором она установлена. Для стабильной работы достаточно будет предустановленной базы данных MySQL и модулей PHP. Системные требования движка также низкие.

Помимо вышеуказанных преимуществ, из главных особенностей «Wordpress» является структура организации БД. Гибкость и функциональность связей позволяют создавать и выводить на страницу материал с самыми различными параметрами, а также визуальной составляющей. Встроенная система «тегирования» создает дополнительные связи для материалов сайта, что при необходимости, позволяет оперировать всеми записями, соответствующими определенным условиям. 
Для установки системы управления контентом WordPress, требуется создать сервер на компьютере. Для этого я использовал Denwer.

Denwer - набор дистрибутивов и программная оболочка, предназначенный для создания и отладки сайтов на локальной Windows-машине.

Для создания сайта выбрана операционная система Microsoft Windows 10 Single Language. Выбор обоснован из-за актуальности данной ОС, все обновления поддерживаются на ней. Также данная операционная система выбрана по причине того, что одной из самых распространенных Windows OS, является Windows 10, на которой все больше пользователей с каждым днем.

На главной странице пользователи могут узнать общую информацию о компании, просматривать ассортимент товара, а также его стоимость, складывать в корзину выбранный товар и создавать заявку заказа. Меню главной страницы состоит из 8 разделов: виски, водка, коньяк, пиво, вино, разное, акции, о компании.

Чтобы заказать нужный клиенту товар, ему необходимо добавлять его в корзину, затем, перейти в корзину и оформить заказ. Необходимо заполнить следующие формы: Фамилия, Имя, Отчество, номер мобильного телефона, адрес (не обязательно, только при заказе с доставкой).

После заполнения всех форм покупателю перезвонит оператор для уточнения заказа и времени. Продажа будет осуществляться строго с 14:00 по 20:00. Так же продажа осуществляется от 2 ящиков алкоголя. Алкогольная продукция будет выдаваться на складе, либо будет производиться доставка.

Разрабатываемый магазин удовлетворяет следующим требованиям:

-Интуитивно понятный интерфейс

-Наличие полной информации о алкогольной продукции (название, цена, описание, дату выпуска и т.п.)

-Содержит информация об истории и деятельности компании.

Список литературы:

1. Сайт "ProWordpress" http://pro-wordpress.ru/ .

2. Сайт "Wikipedia” https://ru.wikipedia.org/wiki/denwer.

3. Сайт "Wordpress.org” https://ru.wordpress.org/ .

4. Сайт “Причал” http://www.priestt.com/article/polza/polza_2348.html. 